\title{
Инфракрасные (850 нм) светодиоды с множественными квантовыми ямами InGaAs и „тыльным“ отражателем
}

\author{
(C) А.В. Малевская ${ }^{1}$, Н.А. Калюжный ${ }^{1}$, Д.А. Малевский ${ }^{1}$, С.А. Минтаиров ${ }^{1}$, А.М. Надточий ${ }^{2}$, \\ М.В. Нахимович ${ }^{1}$, Ф.Ю. Солдатенков ${ }^{1}$, М.З. Шварц ${ }^{1}$, В.М. Андреев ${ }^{1}$ \\ ${ }^{1}$ Физико-технический институт им. А.Ф. Иоффре Российской академии наук, \\ 194021 Санкт-Петербург, Россия \\ ${ }^{2}$ Национальный исследовательский университет „Высшая школа экономики“, \\ 190008 Санкт-Петербург, Россия \\ E-mail: amalevskaya@mail.ioffe.ru
}

Поступила в Редакцию 9 апреля 2021 г.

В окончательной редакции 19 апреля 2021 г.

Принята к публикации 19 апреля 2021 г.

Поведены исследования инфракрасных светодиодов (длина волны 850 нм) на основе гетероструктур $\mathrm{AlGaAs} / \mathrm{GaAs}$, изготовленных методом MOC-гидридной эпитаксии и имеющих множественные квантовые ямы InGaAs в области, генерирующей излучение. Разработаны постростовые приемы по удалению подложки $\mathrm{GaAs}$ и переносу гетероструктуры на инородный носитель с оптическим отражателем. Оптимизированы технологические режимы изготовления отражателя, и достигнуто увеличение коэффициента отражения инфракрасного излучения до 92-93\%. Изготовлены светодиоды с внешней квантовой эффективностью $28.5 \%$.

Ключевые слова: светодиод, гетероструктуры $\mathrm{AlGaAs} / \mathrm{GaAs}$, квантовые ямы InGaAs, текстурирование, отражатели.

DOI: 10.21883/FTP.2021.08.51143.9665

\section{1. Введение}

Для уменьшения внутренних потерь в светоизлучающих диодах (СИД) широко используется технология удаления поглощающей ростовой подложки. В работах [1-3] гетероструктуры $\mathrm{AlGaAs} / \mathrm{GaAs}$ для инфракрасных (ИК) СИД изготавливались методом жидкофазной эпитаксии. Рост структуры начинался с формирования области $\mathrm{Al}_{x} \mathrm{Ga}_{1-x} \mathrm{As}$ толщиной 5-20 мкм с высоким содержанием Al (70-90\%), выполняющей функцию „стоп-слоя“ при последующем удалении (стравливании) подложки. Эффективный вывод излучения из кристалла в таких СИД обеспечивался за счет внутренней фокусировки излучения внутри чипа СИД, имеющего мезаконструкцию [1-4], многократного внутреннего отражения света от поверхностей структуры и переизлучения фотонов в материале активной области при характерном внутреннем квантовом выходе излучательной рекомбинации, близком к $100 \%$. Достигнутые значения мощности излучения в СИД на основе таких жидкофазных многопроходных AlGaAs-гетероструктур с удаленной подложкой и внутренней фокусировкой излучения составляли: $P=50$ мВт при токе 80 мА [1] и $P>150$ мВт при токах $>1 \mathrm{~A}[2,3]$.

Современные мощные ИК СИД (длины волн 800-870 нм) изготавливаются по МОС-гидридной технологии (газофазная эпитаксия из металлоорганических соединений) с последующим „переносом“ гетероструктуры $\mathrm{AlGaAs} / \mathrm{GaAs}$, имеющей предварительно сформированный оптический отражатель, на инородный носитель и с удалением ростовой подложки [5].
Другим методом уменьшения потерь, обусловленных поглощением генерируемого излучения в подложке, является встраивание в структуру брэгговского зеркала [6], слои которого располагаются между излучающим $p-n$-переходом и поглощающей (ростовой) подложкой. В СИД с внутренним брэгговским отражателем максимальная выходная мощность излучения достигает 8 мВт при токе $60 \mathrm{MA} \mathrm{[6].}$

В настоящей работе представлены результаты разработок СИД на основе гетероструктур $\mathrm{AlGaAs} / \mathrm{GaAs}$ с множественными квантовыми ямами в активной области. Поверх сформированной структуры осаждались слои „тыльного“ зеркального покрытия, которые после „переворота“ и переноса эпитаксиальной структуры на инородный носитель (пластина $p^{+}$-GaAs) отделяли область оптической генерации от поглощающей среды $p^{+}$-GaAs. Обсуждаются этапы получения СИД на основе тонкопленочных (толщины < 10 мкм) гетероструктур, в частности процессы переноса и фиксации тонкой структуры на новом носителе, удаления ростовой подложки $(\mathrm{GaAs})$ и формирования электрических контактов.

\section{2. Светоизлучающая гетероструктура AIGaAs-GaAs c квантовыми ямами}

Гетероструктура AlGaAs-GaAs (рис. 1) изготавливалась на установке МОС-гидридной эпитаксии AIX-200/4. Первый слой $\mathrm{Al}_{0.9} \mathrm{Ga}_{0.1}$ As (на рис. 1 не показан) толщиной 0.3 мкм, выращиваемый на подложке 


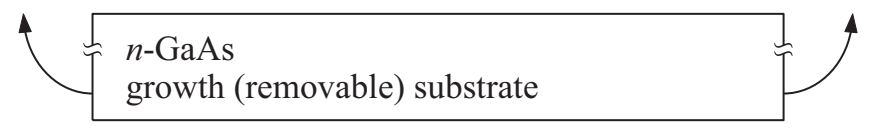

$n^{+}$-GaAs, Bus-bar contact

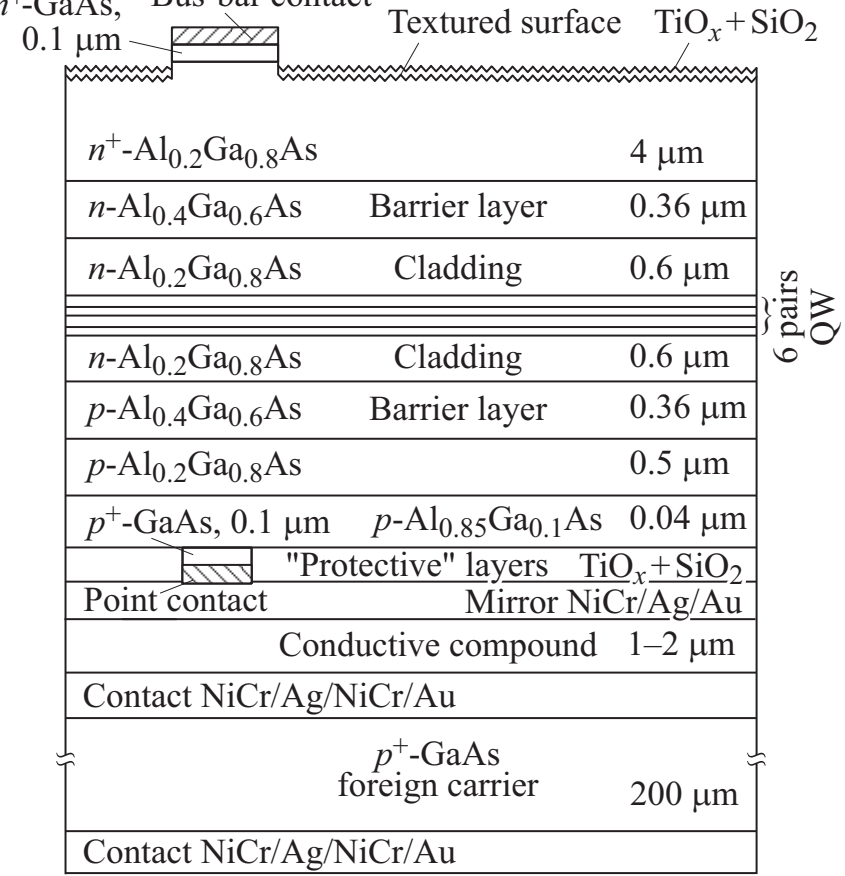

Рис. 1. Схема светодиода после переноса гетероструктуры на пластину-носитель $\left(p^{+}-\mathrm{GaAs}\right)$, удаления ростовой подложки $n$-GaAs, текстурирования световыводящей поверхности и нанесения антиотражающего покрытия.

$n$-GaAs, выполняет, с одной стороны, функцию „стопслоя““ при удалении (стравливании) подложки $n$-GaAs, а с другой - полностью удаляемого „жертвенного“ слоя. На этом этапе „стоп-функция“ уже переходит к слою $n^{+}$-GaAs толщиной 0.1 мкм, который используется затем при изготовлении фронтальных полосковых контактов и удаляется в областях вывода излучения из структуры СИД. Следующий сильно легированный слой $n^{+}-\mathrm{Al}_{0.2} \mathrm{Ga}_{0.8} \mathrm{As}$ толщиной 4 мкм обеспечивает растекание тока по фронтальной поверхности СИД между полосковыми омическими контактами, изготовленными с шагом 150 мкм.

Активная область, заключенная между широкозонными слоями, состоит из 6 пар слоев квантовых ям InGaAs толщиной 3 нм каждая, разделенных слоями $\mathrm{Al}_{0.2} \mathrm{Ga}_{0.8} \mathrm{As}$ толщиной 30 нм каждый. Активная область суммарной толщиной 0.2 мкм с обеих сторон заключена в обкладки $n$ - и $p$-типа проводимости, формируемые парами широкозонных слоев $\mathrm{Al}_{0.2} \mathrm{Ga}_{0.8}$ As (0.6 мкм) и $\mathrm{Al}_{0.4} \mathrm{Ga}_{0.6} \mathrm{As}$ (0.36 мкм).

Затем выращивали переходной слой $p^{+}-\mathrm{Al}_{0.2} \mathrm{Ga}_{0.8} \mathrm{As}$ (0.5 мкм), „стоп-слой“ $p-\mathrm{Al}_{0.85} \mathrm{Ga}_{0.15} \mathrm{As}(0.04$ мкм) и контактный слой $p^{+}$-GaAs (0.1 мкм), стравливаемый в местах, свободных от точечных контактов.

\section{3. Фотолюминесценция квантовых ям светодиодной структуры}

Квантовые ямы (КЯ) широко применяются в качестве активной области светодиодов вследствие ряда преимуществ по сравнению с традиционными „двойными“ гетероструктурами. Во-первых, квантование энергии в КЯ дает высокую степень управления длиной волны излучения и энергетическим спектром путем изменения толщины и состава КЯ. Во-вторых, обеспечивается гибкость в выборе материалов и конструировании активной области. В-третьих, квантовая яма обеспечивает увеличение концентрации носителей в тонком слое и усиление электронно-дырочного перекрытия, что приводит к увеличению скорости излучательной рекомбинации и соответственно к значительному увеличению внутреннего квантового выхода.

Внутренний квантовый выход светодиода напрямую зависит от кристаллического качества активной области и поддержания высокой концентрации носителей в ней. Для оценки ее качества были выращены тестовые структуры с аналогичной конструкцией активной области светодиода, заключенной между барьерными слоями. Активная область тестовой структуры включала шесть КЯ InGaAs/ $/ \mathrm{Al}_{0.2} \mathrm{Ga}_{0.8} \mathrm{As}$, заключенных между слоями $\mathrm{Al}_{0.2} \mathrm{Ga}_{0.8} \mathrm{As}$. Барьерные слои $\mathrm{Al}_{0.4} \mathrm{Ga}_{0.6} \mathrm{As}$ предотвращали выброс носителей за пределы активной области.

Спектры фотолюминесценции (ФЛ) тестовых структур записывались в режимах комнатной и азотной температур при двух плотностях оптического возбуждения YAG:Nd-лазером с длиной волны излучения 532 нм (рис. 2). Оптическое разрешение обеспечивалось мо-

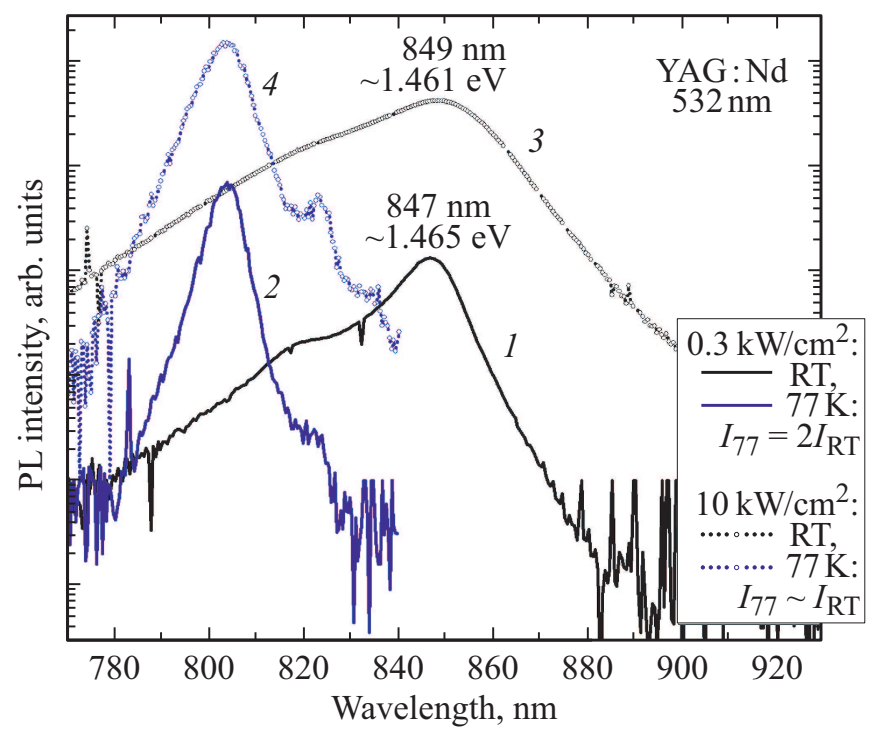

Рис. 2. Спектры фотолюминесценции (PL) для тестовой структуры на основе шести КЯ $\mathrm{InGaAs} / \mathrm{Al}_{0.2} \mathrm{Ga}_{0.8} \mathrm{As}$ : 1,3 комнатная температура (RT), 2,4 - температура жидкого

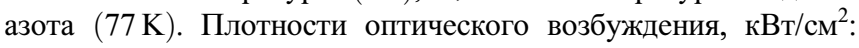
$1,2-0.3 ; 3,4-10$. 
нохроматором МДР-23 с регистрацией сигнала ФЛ охлаждаемым германиевым фотодиодом по стандартной методике синхронного детектирования. Исследование ФЛ при различных плотностях возбуждения позволило оценить работу активной среды светодиода при повышенных плотностях тока.

Интенсивный пик ФЛ наблюдается при комнатной

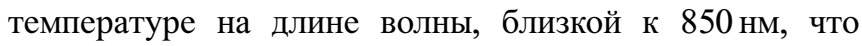
соответствует расчету по твердотельной модели КЯ [7] для соответствующей толщины и состава КЯ. Коротковолновое плечо в спектре ФЛ при комнатной температуре соответствует возбужденному состоянию. При увеличении лазерной накачки соотношение интенсивностей пиков ФЛ (форма спектров) сохраняется. Это показывает, что излучение генерируется главным образом через основное состояние в КЯ и насыщение данного рекомбинационного канала отсутствует. Такой механизм не характерен для структур с одной КЯ, в которых с увеличением уровня накачки доминирует возбужденное состояние. Других пиков, в частности от подложки GaAs, в спектре ФЛ при комнатной температуре не наблюдается, что свидетельствует об эффективном захвате инжектированных носителей активной областью и о доминирующей рекомбинации через КЯ при комнатной температуре.

Для структуры характерна высокая температурная стабильность ФЛ: соотношение интегральных интенсивностей фотолюминесценции, измеренных при $77 \mathrm{~K}$ и комнатной температуре $\left(I_{77} / I_{\mathrm{RT}}\right)$, составило 2 и 1 (уже с учетом потерь, вносимых сосудом Дьюара) при низкой и высокой накачке соответственно, что свидетельствует о высоком качестве активной среды и малой плотности центров безызлучательной рекомбинации.

\section{4. Технология переноса гетероструктуры на инородный носитель и изготовление светодиодов}

Процесс переноса гетероструктуры на пластинуноситель выполнялся в несколько стадий. Сначала на поверхности выращенной гетероструктуры создавались точечные контакты (диаметр 10 мкм, шаг 75 мкм) к контактному слою $p^{+}$-GaAs путем осаждения слоев $\mathrm{NiCr} / \mathrm{Ag} / \mathrm{NiCr} / \mathrm{Au}$ и их последующего отжига. Затем осуществлялось селективное удаление контактного слоя в местах, свободных от контактов, что обеспечивало формирование прозрачных окон для выходящего (генерируемого) излучения.

Поверхность таких окон закрывалась диэлектрическим покрытием $\mathrm{TiO}_{x} / \mathrm{SiO}_{2}$. Сплошное зеркальное покрытие на основе слоев сплава никель-хром, серебра и золота $(\mathrm{NiCr} / \mathrm{Ag} / \mathrm{Au})$, составляющих тыльный отражатель, напылялось на всю поверхность структуры, включая точечные контакты и оптические окна с диэлектриком. Слой диэлектрика использовался для исключения

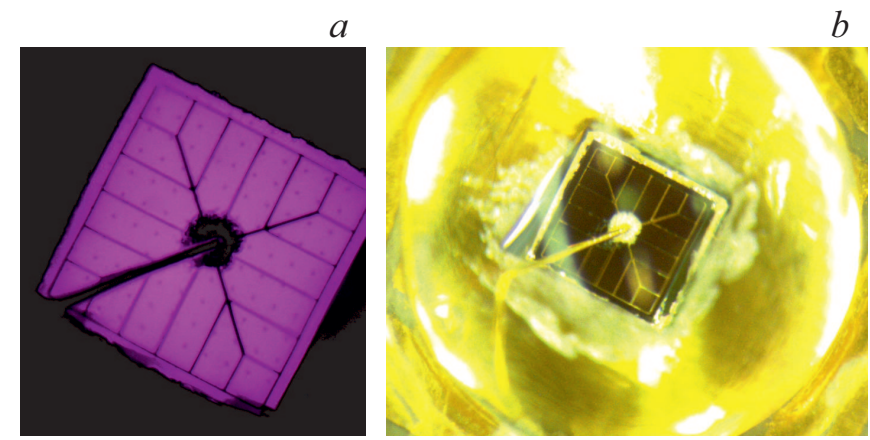

Рис. 3. Фотографии электролюминесценции изготовленного светодиода площадью $1 \mathrm{mм}^{2}(a)$ и светодиода с силиконовой полусферой диаметром 3 мм $(b)$.

непосредственного контакта полупроводника с металлическими слоями зеркального покрытия и предотвращения возможной деградации оптических свойств зеркала. Подслой сплава $\mathrm{NiCr}$ толщиной 1 нм служил для усиления адгезии слоя $\mathrm{Ag}$ к поверхности диэлектрика, тонкий слой золота - для пассивации поверхности Ag.

Поверх отражателя наносился слой серебросодержащего токопроводящего компаунда (толщина слоя 1-2 мкм), структура переворачивалась и фиксировалась на пластине-носителе $p^{+}$-GaAs, имеющей предварительно осажденные контактные слои $\mathrm{NiCr} / \mathrm{Ag} / \mathrm{NiCr} / \mathrm{Au}$ на фронтальной (контактирующей с гетероструктурой) и тыльной (обращенной вниз, см. рис. 1) поверхностях. Для стабилизации соединительного компаунда использовался прогрев при $140^{\circ} \mathrm{C}$ в течение 10 мин.

Финальная стадия заключалась в удалении основного объема ростовой подложки $n$-GaAs в растворе на основе аммиака и перекиси водорода $\left(\mathrm{NH}_{4} \mathrm{OH}+\mathrm{H}_{2} \mathrm{O}_{2}\right)$ вплоть до появления „стоп-слоя“ $\mathrm{Al}_{0.9} \mathrm{Ga}_{0.1} \mathrm{As}$, а затем в контролируемом очищении поверхности от $n$-GaAs в травителе на основе лимонной кислоты и перекиси водорода. „Стоп-слой“ $\mathrm{Al}_{0.9} \mathrm{Ga}_{0.1} \mathrm{As}$ селективно стравливался до контактного слоя $n^{+}$-GaAs в горячей $\left(70-80^{\circ} \mathrm{C}\right)$ соляной кислоте. Для увеличения эффективности вывода излучения из гетероструктуры проводилось текстурирование световыводящей поверхности (в местах, свободных от контактов), формирование просветляющего покрытия на основе слоев $\mathrm{TiO}_{x} / \mathrm{SiO}_{2}$, формирование фронтальных полосковых омических контактов к слою $n^{+}$-GaAs, coздание разделительной мезаструктуры.

Готовые чипы СИД монтировались на теплоотводящие основания и закрывались формирователем светового потока типа „полусфера“ (рис. 3).

\section{5. Оптические характеристики „тыльного“ отражателя}

При изготовлении гетероструктуры для СИД критическим было определение оптической эффективности 


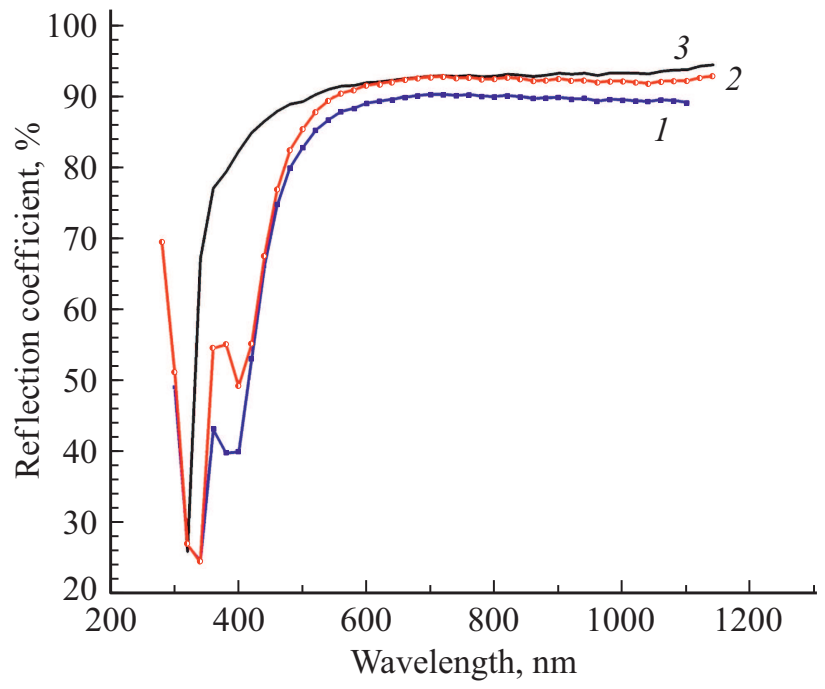

Рис. 4. Зависимость коэффициента отражения изотропного излучения от длины волны для отражателей на основе: $1-$ стекло + диэлектрик $+\mathrm{NiCr}(2 \mathrm{HM})+\mathrm{Ag}, 2-$ стекло + диэлектрик $+\mathrm{NiCr}(1 \mathrm{Hм})+\mathrm{Ag}, 3-$ стекло + Ag. Измерения проводились при подводе излучения к образцу со стороны стекла.

тыльного зеркального отражателя. Спектральные зависимости коэффициента отражения для тестовых образцов зеркал, формируемых на стекле с адгезионным слоем (сплав $\mathrm{NiCr}$ ) различной толщины, определялись в диапазоне длин волн излучения 300-1150 нм с использованием интегрирующей сферы и спектрорадиометра. Значения коэффициентов отражения для образцов с одиночным адгезионным слоем $\mathrm{NiCr}$ толщиной $\sim 1 \mathrm{Hм}$ и одним слоем серебра практически совпадают и составляют $\sim 93 \%$ на длине волны 850 нм (рис. 4). При увеличении толщины адгезионного слоя до 2 нм наблюдалось снижение коэффициента отражения зеркального покрытия до 90\%.

Исследования стабильности зеркального покрытия и его температурной стойкости проводились при температурах до $400^{\circ} \mathrm{C}$, что соответствует температурному режиму отжига полосковых контактов. Деградации оптических свойств зеркала обнаружено не было.

\section{6. Характеристики светодиодов}

Были выполнены исследования внешней квантовой эффективности, вольт-амперных и ватт-амперных характеристик светодиодов, полученных с использованием разработанных технологий. Измерения проводились в широком диапазоне пиковых токов, пропускаемых через СИД в импульсном режиме, что исключало неконтролируемый перегрев прибора в процессе измерения. Схема экспериментальной установки представлена на рис. 5. Для регистрации излучения, генерируемого СИД, в непосредственной близости от него располагается кон- трольный фотоприемник с известной спектральной чувствительностью на длине волны излучения светодиода.

Формирование токовых импульсов осуществлялось биполярным операционным усилителем по командам от цифроаналогового преобразователя, который одновременно обеспечивал запись вольт-амперных характеристик СИД и регистрацию тока контрольного фотоприемника. Общее управление установкой осуществлялось по программе от персонального компьютера. Функционал биполярного операционного усилителя позволял в широких диапазонах варьировать длительность (> 50 мкс) и скважность импульсов тока. Факт отсутствия нагрева СИД контролировался путем регистрации серий вольти ватт-амперных характеристик с различной длительностью токовых импульсов.

На рис. 6 представлены токовые зависимости внешней квантовой эффективности (EQE) (кривая 1) и выходной оптической мощности (кривая 2) СИД, изготовленного с использованием разработанных эпитаксиальной и постростовой технологий. Достигнутое значение EQE СИД (площадь $S=1 \mathrm{Mм}^{2}$ ) с силиконовой полусферой диаметром 3 мм составило 28.5\% при токах 100-130 мА.

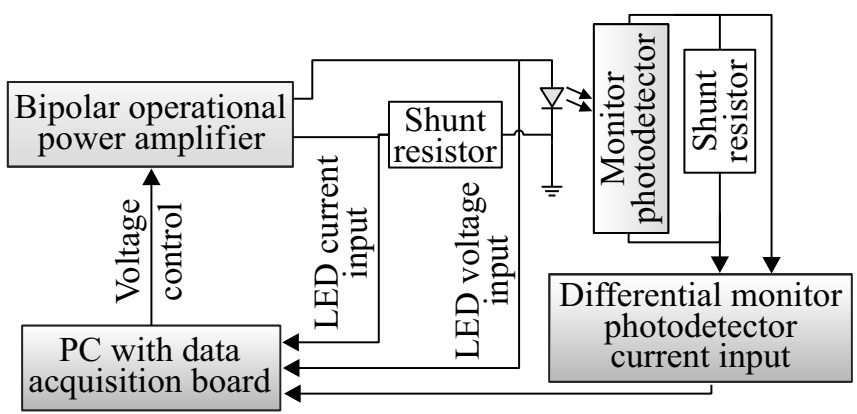

Рис. 5. Блок-схема установки для измерения внешней квантовой эффективности, вольт- и ватт-амперных характеристик СИД.

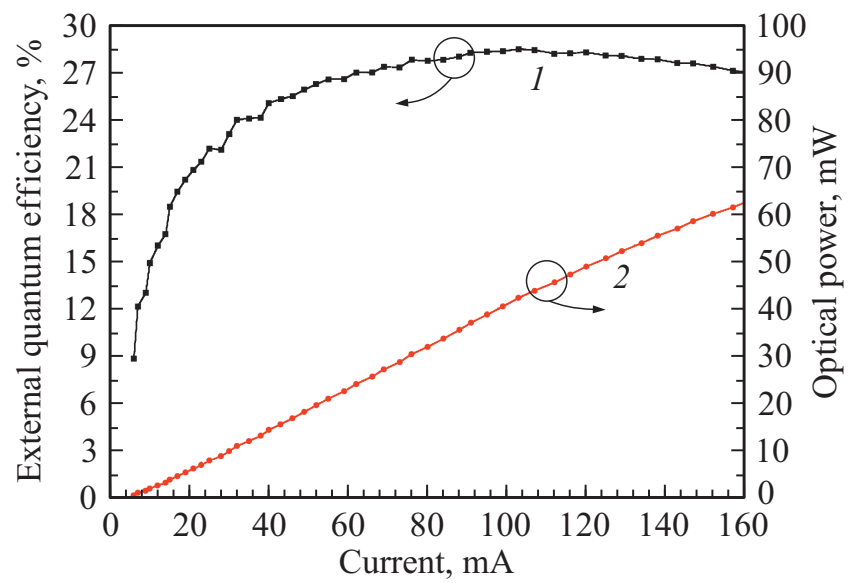

Рис. 6. Токовые зависимости внешней квантовой эффективности (1) и выходной оптической мощности (2) для СИД $(\lambda=850$ нм $)$, изготовленных методом „переноса“ гетероструктуры $\mathrm{AlGaAs} / \mathrm{GaAs}$ на носитель с оптическим отражателем. 


\section{7. Заключение}

Разработаны ИК светодиоды (на длину волны 850 нм) на основе гетероструктур $\mathrm{AlGaAs} / \mathrm{GaAs}$ с множественными квантовыми ямами в активной области, изготовленных методом МОС-гидридной эпитаксии. Выполнены исследования технологии формирования серебряного отражателя с подслоем из сплава $\mathrm{Ni}$ и $\mathrm{Cr}$, и достигнуто увеличение коэффициента отражения до 92-93\% на длине волны 850 нм. Разработана процедура „переноса“ структуры с отражателем на пластину-носитель с последующим стравливанием ростовой подложки $n$-GaAs. Отработана постростовая технология изготовления полосковых омических контактов на тонкой (<10 мкм) эпитаксиальной гетероструктуре, фиксированной на пластине-носителе, и методика текстурирования световыводящей поверхности для увеличения эффективности вывода света из кристалла. Изготовлены СИД с величиной внешней квантовой эффективности $28.5 \%$.

\section{Благодарности}

Авторы выражают благодарность Н.Д. Ильинской, Ю.М. Задиранову, П.В. Покровскому, А.Н. Паньчаку, Р.А. Салию, Н.С. Потапович, А.А. Блохину, А.В. Андреевой за помощь и консультации при проведении экспериментов. А.М. Надточий благодарит за поддержку в области исследований методом фотолюминесценции Программу фундаментальных исследований НИУ ВШЭ в 2021 г.

\section{Конфликт интересов}

Авторы заявляют, что у них нет конфликта интересов.

\section{Список литературы}

[1] Ж.И. Алфёров, В.М. Андреев, Д.3. Гарбузов, Н.Ю. Давидюк, Б.В. Егоров, Б.В. Пушный, Л.Т. Чичуа. ФТП, 48 (4), 809 (1978).

[2] У. Бекирев, С. Бабенко, В. Крюков, Б. Потапов, А. Скипер. Электроника НТБ, 00137, 137 (2014).

[3] Электронный ресурс АО „Научно-исследовательский институт полупроводниковых приборов“ $\mathrm{https} / / /$ www.niipp.ru/

[4] S. Ilelek, A. Plossol, K. Streubel, W. Wegleiter, R. Wirth. Patent US 2006/0180820 A1 (2006).

[5] https://www.epistar.com/EpistarEn/prodInfo

[6] Su-Chang Ahn, Byung-Teak Lee, Won-Chan An, DaeKwang Kim, In-Kyu Jang, Jin-Su So, Hyung-Joo Lee. Phys. Soc., 69 (1), 91 (2016).

[7] C.G. Van de Walle. Phys. Rev., 39, 1871 (1989).

\section{Infrared $(850 \mathrm{~nm})$ light-emitting diodes with multiple InGaAs quantum wells and „back" reflector}

\author{
A.V. Malevskaya ${ }^{1}$, N.A. Kalyuzhnyy ${ }^{1}$, D.A. Malevskii ${ }^{1}$, \\ S.A. Mintairov ${ }^{1}$, A.M. Nadtochiy ${ }^{2}$, M.V. Nakhimovich ${ }^{1}$, \\ F.Y. Soldatenkov' ${ }^{1}$, M.Z. Shvarts ${ }^{1}$, V.M. Andreev ${ }^{1}$ \\ ${ }^{1}$ loffe Institute, \\ 194021 St. Petersburg, Russia \\ 2 National Research University \\ Higher School of Economics, \\ 190008 St. Petersburg, Russia
}

Abstract Investigation of IR light emitting diodes (wavelength $850 \mathrm{~nm}$ ) based on $\mathrm{AlGaAs} / \mathrm{GaAs}$ heterostructures with multiple quantum wells InGaAs in the region generating radiation, grown by the MOCVD technique, has been carried out. Post-growth technologies for removing the growth substrate and for transfer the heterostructure on an alien carrier with an optical reflector have been developed. Technological regimes for fabricating the reflector has been optimized and the increase of the IR radiation reflection coefficient up to $92-93 \%$ has been achieved. Lightemitting diodes with the external quantum efficiency of $28.5 \%$ have been fabricated.

Редактор Л.В. Шаронова 